\title{
Structural and Thermophysical Studies of Composite Na-Cobaltite Electrospun Nanofibers
}

\author{
Fatima-tuz-Zahra and M. Anis-ur-Rehman \\ Applied Thermal Physics Laboratory, Department of Physics, COMSATS Institute of Information Technology, \\ Islamabad 44000, Pakistan \\ Correspondence should be addressed to M. Anis-ur-Rehman; marehman@comsats.edu.pk
}

Received 28 June 2015; Revised 17 October 2015; Accepted 18 October 2015

Academic Editor: Tong Lin

Copyright (C) 2015 Fatima-tuz-Zahra and M. Anis-ur-Rehman. This is an open access article distributed under the Creative Commons Attribution License, which permits unrestricted use, distribution, and reproduction in any medium, provided the original work is properly cited.

\begin{abstract}
Polymeric nanofibers have been produced in the last few years by electrospinning of polymer solutions. Polyvinyl alcohol (PVA) was the selected polymer for the preparation of nanofibers. Processing parameters like flow rate, needle gauge, needle to collector distance, and molarity of the solution have been optimized during electrospinning process. Sol-gel method has been used for the preparation of thermoelectric cobaltite nanoparticles having composition $\mathrm{NaCoO}_{2}$. Sol-gel combined electrospinning technique was used to prepare the composites of the $\mathrm{NaCoO}_{2}$ with PVA nanofibers. X-ray diffraction (XRD), thermogravimetric analysis (TGA), and differential scanning calorimetry (DSC) have been used for the structural analysis of the prepared samples. Scanning electron microscopy (SEM) was used to observe the morphology of the prepared fibers. SEM micrographs showed that, by increasing the flow rate, diameter of the fibers increased from $185 \mathrm{~nm}$ to $200 \mathrm{~nm}$. Two-probe method and Advantageous Transient Plane Source (ATPS) were used to study the electrical and thermal transport properties, respectively. Thermal conductivity and electrical conductivity showed a direct dependence on temperature. It was observed that particles, sample has lower thermal conductivity $(0.610 \mathrm{~W} / \mathrm{m}-\mathrm{K})$ as compared to that of composite nanofibers $(1.129 \mathrm{~W} / \mathrm{m}-\mathrm{K})$. The measurements reported are novel and are useful for energy applications.
\end{abstract}

\section{Introduction}

Electrospinning technique has been used for the preparation of nanofibers. Electrospinning is the latest technique used to produce nanostructures (nanofibers) of controlled size and fine morphology for desirable properties. Electrospinning is one of the most versatile techniques for the fabrication of nanofibers. The major components of electrospinning unit include metal needle (spinneret), collector, flow pump, and voltage supply. There are different major processing parameters of electrospinning unit, alteration of which can lead to significant effects on the morphology of the nanofibers. These parameters include flow rate, needle to collector distance, applied electric potential, and molarity of the solutions being processed [1-3]. Combining sol-gel method with electrospinning makes it more convenient for the production of composite nanofibers. Homogeneity can be achieved by solgel combined electrospinning method since the different stages involved in sol-gel method get confined within small space, that is, the spinneret [4].

Currently the world is going through energy crises and researchers are looking for the solutions to get through them. Nanoscience is emerging as a promising field to overcome these problems. Many materials are being studied to resolve the problems among those materials; thermoelectric materials are of great interest because of their different advantages such as these material having no moving parts so no maintenance is required and also their efficiency makes them dominant over other materials. Thermoelectric materials convert thermal energy into electrical energy by utilizing Seebeck effect which makes them applicable for power generation. Thermocouple is another device which is fabricated using these materials for temperature measurements $[5,6]$. To enhance the cooling efficiency of refrigerators, Peltier effect is utilized by which the applied electrical potential causes the evolution and absorbance of 
heat at respective junctions of two dissimilar materials $[5,7]$. The efficiency of thermoelectric materials is quantified by dimensionless figure of merit ZT $=S^{2} \sigma T / \lambda$, where $S$ is Seebeck coefficient, $\sigma$ is electrical conductivity, $T$ is absolute temperature, and $\lambda$ is thermal conductivity. ZT is higher for materials with low thermal conductivity and high electrical conductivity [8]. Depending upon their structural properties, thermoelectric materials are subdivided into three major categories, Skutterudites, half Heuslers, and oxides. Cobaltites are the subcategory of oxides thermoelectric materials possessing the high electrical conductivity and low thermal conductivity and hence good thermoelectric properties [9]. Usually these materials have layered structure which plays a significant role in the enhancement of their thermoelectric properties.

Sodium cobaltite is one of the layered cobaltites. Due to its layered structure, it possesses high electrical conductivity and low thermal conductivity and hence high Seebeck coefficient. The phonon scattering causes reduction in the thermal conductivity of the material while strong electronelectron correlation makes this material an efficient electrical conductor [10].

Nanofibers of sodium cobaltite are prepared by various researchers to enhance their thermoelectric properties [11]. The chained structure of polymer plays a vital role in manipulation of thermoelectric properties of cobaltites. Electrical conductivity of the polymers increases due to their chain length due to the formal mechanism of electrical conductivity (electron hopping) along the backbone of the polymers [12]. Thermal conductivity also increases with chain length of polymers as reported by various researchers [13, 14]. Hence the thermoelectric properties are highly dependent on the chain length of the selected polymer for preparation of composite nanofibers [15]. So, the thermoelectric properties can be enhanced by preparing the composite nanofibers of the material [16]. And as mentioned earlier electrospinning is the most suitable technique for the preparation of composite nanofibers because of the proper control over its processing parameters.

The aim of the present work is to prepare the nanoparticles of $\mathrm{NaCoO}_{2}$ by using sol-gel method and their composite nanofibers by using sol-gel combined electrospinning technique. The effect of synthesis route on the different properties (structural, electrical, and thermal) of the $\mathrm{NaCoO}_{2}$ and their composite nanofiber is studied.

\section{Experimental Procedure}

Sodium cobaltite nanoparticles and their respective composite nanofibers were prepared by sol-gel method and sol-gel combined electrospinning technique, respectively. Precursors used for the synthesis of nanoparticles were $\mathrm{NaNO}_{3}$ and $\mathrm{Co}\left(\mathrm{NO}_{3}\right)_{2} \cdot 6 \mathrm{H}_{2} \mathrm{O}$. The precursors were added in ethylene glycol which was used as a gelling agent. The solution was magnetically stirred at room temperature for 1 hour to attain homogeneity. The homogeneous solution was further heated for the gel formation. The gel was burned at higher temperature which was further processed through grinding to get the desired nanoparticles in powder form. The calcination of the powder was done at $450^{\circ} \mathrm{C}$ for two hours with a heating rate of $25^{\circ} \mathrm{C} / \mathrm{min}$. The calcined powder was pressed into pellets of diameter $\sim 13 \mathrm{~mm}$ and thickness $\sim 4 \mathrm{~mm}$ at a pressure of 1000 psi for 15 minutes. The pellets were sintered at a temperature of $550^{\circ} \mathrm{C}$ for two hours (heating rate $25^{\circ} \mathrm{C} / \mathrm{min}$ ) to attain the better crystallinity.

For the preparation of the composite nanofibers, sodium cobaltite was cosynthesized with polyvinyl alcohol (PVA) nanofibers. Two major steps are involved in the solution preparation: polymer solution preparation and precursor solution preparation.

PVA $(89,000 \mathrm{~g} / \mathrm{mol})$ polymer was used for the preparation of polymer solution. $0.0006 \mathrm{M}$ solution of PVA was prepared with deionized water (50\%) and ethanol (50\%) as its solvent. The solution was magnetically stirred at room temperature to acquire a homogeneous polymer solution.

Precursors used for sol-gel combined electrospinning were the same as those used in sol-gel method. The precursor solution was prepared by individual mixing of the precursors with their respective solvents. Ethanol was used as solvent for both precursors while the molarity for both was kept $0.2 \mathrm{M}$. The individually prepared precursors were then added together and magnetically stirred to get the desired precursors solution. Both solutions were further mixed together and heated at $70 \pm 5^{\circ} \mathrm{C}$ with continuous stirring for better homogeneity. The resulting solution was processed through electrospinning to attain the composite nanofibers. The prepared samples were analyzed for their different properties such as structural, electrical, and thermal transport properties.

\section{Results and Discussion}

Structural analysis of the prepared particles was done using X-ray diffraction (XRD), scanning electron microscopy (SEM), thermogravimetric analysis (TGA), and differential scanning calorimetry (DSC), while the structural analysis of the prepared composite nanofibers was done using XRD and SEM. Electrical properties of the prepared particles were studied as a function of frequency as well as temperature. Frequency dependent ac electrical properties that included ac conductivity $\left(\sigma_{\mathrm{ac}}\right)$ and dielectric loss tangent $(\tan \delta)$ were studied for particles and composite nanofibers within a frequency range of $20 \mathrm{~Hz}-3 \mathrm{MHz}$ at room temperature. DC electrical properties of the particles as a function of temperature were studied using two-probe method within a temperature range of $30-450^{\circ} \mathrm{C}$.

3.1. Structural Analysis of the Particles. XRD, SEM, and TGADSC were used for the structural analysis of the prepared particles. Figure 1 shows the XRD patterns of the prepared particles. It was observed that the prepared particles possessed primitive orthorhombic crystal structure with a space group PNNM. No extra peak was observed which shows the good phase purity of the samples. The crystallite size corresponding to the major peaks was calculated using the 


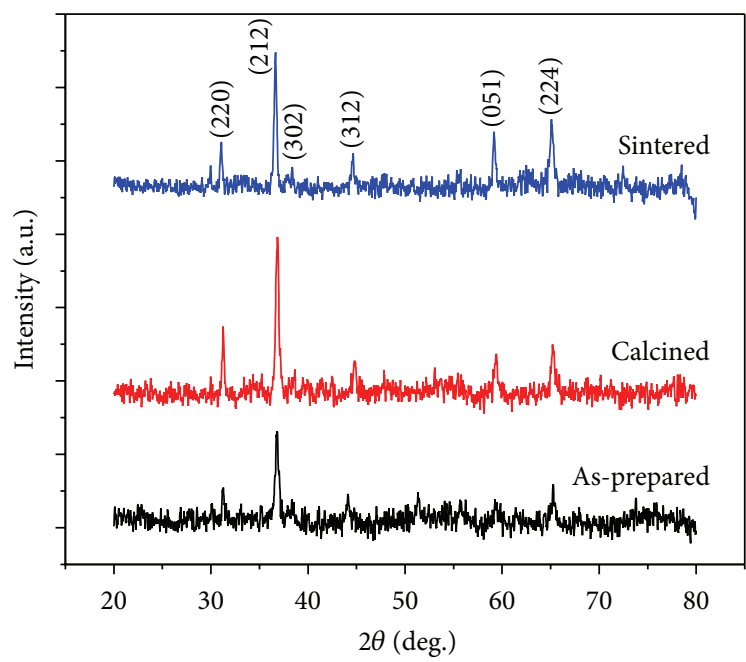

FIGURE 1: XRD patterns of as prepared, calcined, and sintered $\mathrm{NaCoO}_{2}$ particles.

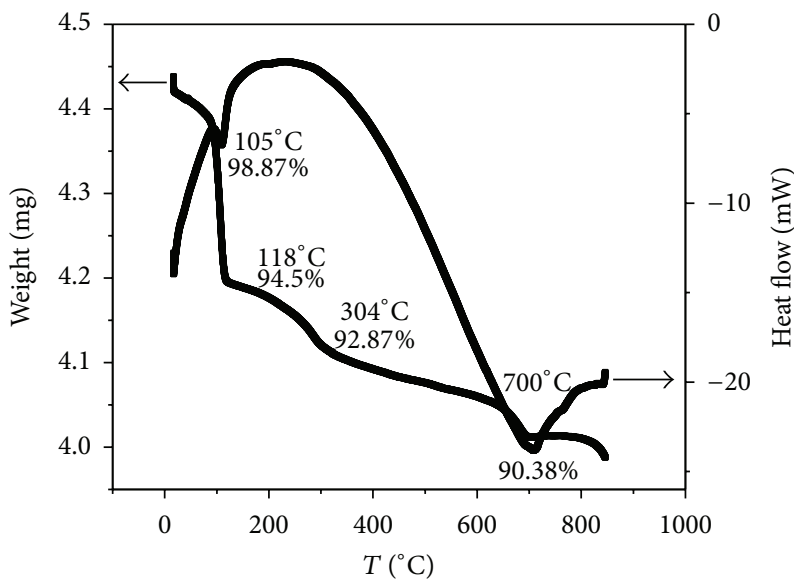

FIgUre 2: TGA/DSC plots of $\mathrm{NaCoO}_{2}$ particles.

Scherrer formula and these were within the range of 32$46 \mathrm{~nm}$. Porosity was calculated using the following formula:

$$
P=\left(1-\frac{\rho_{\mathrm{exp}}}{\rho_{\mathrm{th}}}\right) \times 100,
$$

where $\rho_{\text {th }}$ is the calculated theoretical density using XRD data and $\rho_{\exp }$ is the experimental density obtained from mass and volume of the samples. All these calculated parameters for asprepared, calcined, and sintered samples are given in Table 1.

The SEM was done to study the morphology of the prepared nanoparticles of $\mathrm{NaCoO}_{2}$. Figure 2 shows the SEM micrographs of the prepared nanoparticles. Homogeneous particle size distribution was observed for the prepared sample. The estimated average particle size was $143 \mathrm{~nm}$.

3.2. TGA-DSC Analysis of the Particles. Figure 3 shows the TGA-DSC plots of the prepared particles. TGA-DSC analysis of the prepared particles was done to study the thermal stability and to optimize the sintering temperature of the prepared
TABLE 1: Measured parameters using XRD data, crystallite size corresponding to maximum peak $\left(D_{\max }\right)$, lattice constants $(a, b$, $c)$, volume of unit cell $(V)$, theoretical density $\left(\rho_{\text {th }}\right)$, experimental density $\left(\rho_{\text {exp }}\right)$, porosity $(P)$, and activation energy $\left(E_{g}\right)$ determined from temperature dependent dc resistivity.

\begin{tabular}{lc}
\hline Sample & $\mathrm{NaCoO}_{2}$ \\
\hline Crystallite size $\left(D_{\max }\right) \pm 1(\mathrm{~nm})$ & 42 \\
As-prepared & \\
Crystallite size $\left(D_{\max }\right) \pm 1(\mathrm{~nm})$ & 34 \\
Calcined & \\
Crystallite size $\left(D_{\max }\right) \pm 1(\mathrm{~nm})$ & 46 \\
Sintered & $a=8.22(2)$ \\
Lattice constants $(\AA)$ & $b=7.95(2)$ \\
As-prepared & $c=6.56(5)$ \\
& $a=8.177(6)$ \\
Lattice constants $(\AA)$ & $b=7.98(1)$ \\
Calcined & $c=6.53(1)$ \\
& $a=8.24(5)$ \\
Lattice constants $(\AA)$ & $b=7.98(5)$ \\
Sintered & $c=6.55(2)$ \\
Volume of unit cell $\left(\AA^{3}\right)$ & 428.90 \\
As-prepared & \\
Volume of unit cell $\left(\AA^{3}\right)$ & 426.54 \\
Calcined & \\
Volume of unit cell $\left(\AA^{3}\right)$ & 430.72 \\
Sintered & \\
Theoretical density $\left(\rho_{\text {th }}\right)$ & \\
g/cm & \\
Experimental density $\left(\rho_{\text {exp }}\right)$ & \\
g/cm & \\
Porosity $(\%)$ & \\
Activation energy $\left(E_{g}\right)$ eV & \\
\hline & \\
& \\
& \\
&
\end{tabular}

sample. From TGA plot, first weight loss was observed at $105^{\circ} \mathrm{C}$ which corresponded to the evacuation of the moisture from the sample. The weight loss was also observed at $118^{\circ} \mathrm{C}$ and $305^{\circ} \mathrm{C}$ which corresponded to the evaporation of the trapped nitrates within the sample which were used as precursors. No major loss was further observed. 9.62\% of the total weight was lost which interpreted the good thermal stability of the sample.

In DSC plot first endothermic peak was observed at $105^{\circ} \mathrm{C}$ which correspond to the glass transition peak. No further peak was observed until $700^{\circ} \mathrm{C}$. The crystallization started from about $300^{\circ} \mathrm{C}$. At $700^{\circ} \mathrm{C}$ another endothermic peak was observed which corresponds to the melting temperature of the sample.

3.3. Structural Analysis of Composite Nanofibers. XRD and SEM techniques were used for the structural analysis of the prepared composite nanofibers. Figure 4 shows the XRD pattern of the composite nanofibers. XRD analysis confirmed the presence of the particles embedded within the nanofibers. XRD plots showed that composite fibers possess hexagonal crystal structure of space group P6 with lattice constants $a=b=3.82(4) \AA$ and $c=15.58(2) \AA$. The structure of 

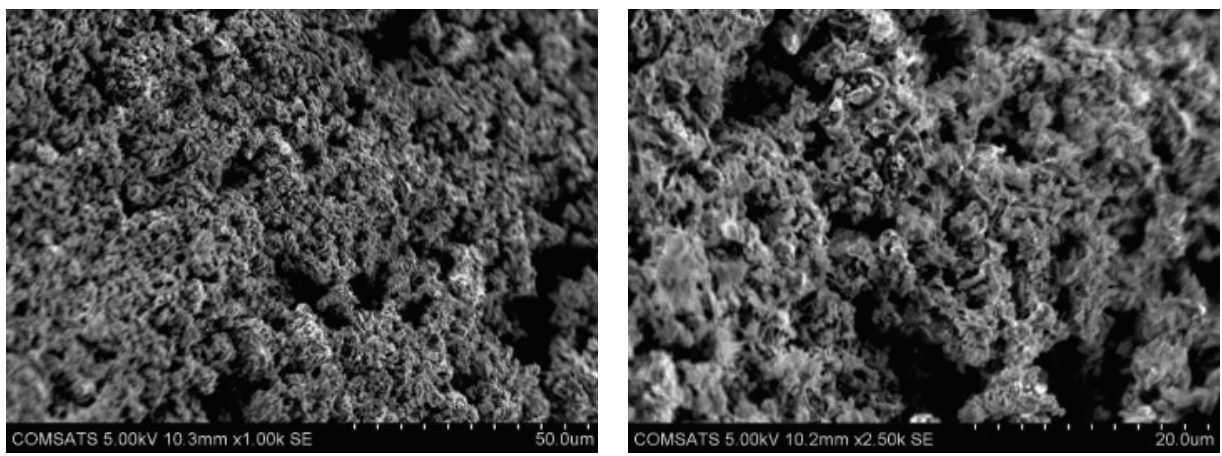

FIGURE 3: SEM micrographs of $\mathrm{NaCoO}_{2}$ particles at different resolutions.

TABle 2: Parameters optimized for the preparation of composite nanofibers.

\begin{tabular}{lccccc}
\hline $\begin{array}{l}\text { Molarity of } \\
\text { precursor sol. }(\mathrm{M})\end{array}$ & $\begin{array}{c}\text { Molarity of } \\
\text { polymer sol. }(\mathrm{M})\end{array}$ & $\begin{array}{c}\text { Flow rate } \\
(\mathrm{mL} / \mathrm{hr})\end{array}$ & $\begin{array}{c}\text { Needle size } \\
(\mathrm{G})\end{array}$ & $\begin{array}{c}\text { Needle to collector } \\
\text { distance }(\mathrm{cm})\end{array}$ & $\begin{array}{c}\text { Voltage } \\
\text { source }(\mathrm{kV})\end{array}$ \\
\hline 0.2 & $0.0006(\mathrm{PVA})$ & 0.5 & 22 & 8 & 20 \\
\hline
\end{tabular}

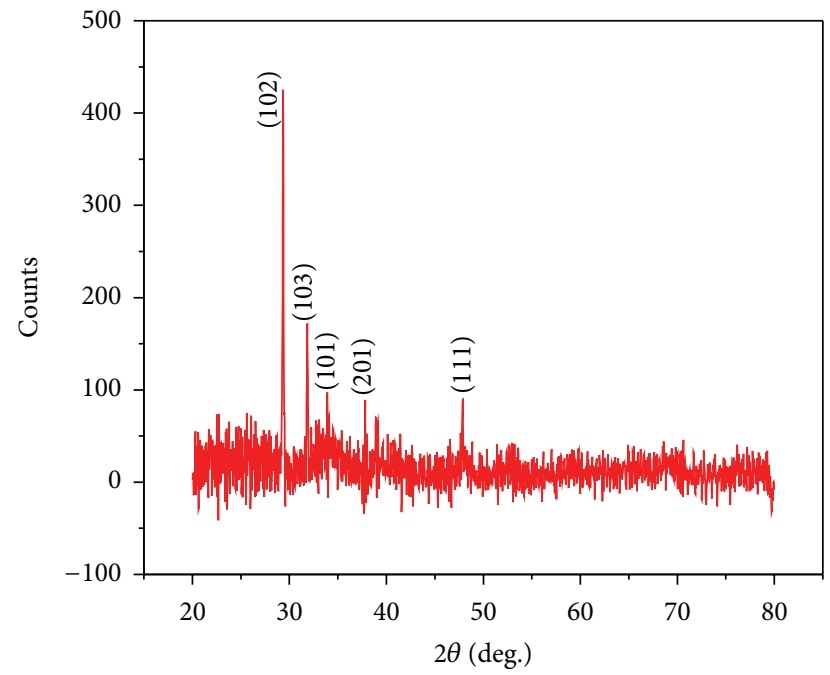

FIGURE 4: XRD patterns of composite nanofibers of $\mathrm{NaCoO}_{2}$.

the composites was different from that of the nanoparticles due to the difference of the synthesis technique. The crystallite sizes were within the range of $42-82( \pm 1) \mathrm{nm}$.

Figures 5(a) and 5(b) show the SEM micrographs of the nanofibers of PVA and the composite nanofibers, respectively. PVA nanofibers were first prepared by optimization of different processing parameters during electrospinning process such as molarity, flow rate, needle gauge, and needle to collector distance. Table 2 shows the optimized parameters for the fiber synthesis. Fine morphology of the nanofibers and composite nanofibers was observed by SEM. The average diameter of the composite nanofibers was $128 \mathrm{~nm}$.

3.4. Electrical Properties of Particles. DC electrical properties of the prepared particles were studied as a function of temperature in a temperature range of $30-450^{\circ} \mathrm{C}$.
AC electrical properties were studied at room temperature within a frequency range of $20 \mathrm{~Hz}-3 \mathrm{MHz}$. Figure 6(a) shows the electrical resistivity $\left(\rho_{\mathrm{dc}}\right)$ plot of the prepared particles, Figure 6(b) shows the Arrhenius plot for the determination of activation energy, and Figure 6(c) shows drift mobility $\mu_{d}$ as a function of temperature for $\mathrm{NaCoO}_{2}$ nanoparticles. Value of activation energy is given in Table 1. DC electrical resistivity $\left(\rho_{\mathrm{dc}}\right)$ was measured for the prepared particles. Semiconducting behavior of the sample was observed. The resistivity decreased with increase in temperature which corresponded to the increase in conductivity of the particles. The resistivity was measured using two-probe method and the following formula was utilized for the calculations:

$$
\rho_{\mathrm{dc}}=R \frac{L}{A},
$$

where $R, L$, and $A$ are the measured resistance, thickness, and area of the sample.

AC electrical properties were measured using LCR meter. AC electrical conductivity $\left(\sigma_{\mathrm{ac}}\right)$ and dielectric loss tangent $(\tan \delta)$ were measured as a function of frequency within a frequency range of $20 \mathrm{~Hz}-3 \mathrm{MHz}$. Figures 7 (a) and 7(b) show the plots of the ac electrical conductivity $\left(\sigma_{\mathrm{ac}}\right)$ and dielectric loss tangent $(\tan \delta)$, respectively. There are different polarization phenomena that affect the ac electrical properties of the material. The intrinsic dipole moments when interacting with the applied electric field tend to align themselves according to the frequency of the applied field. Their alignment frequency defines the dielectric behavior of the sample for the applied frequency. Polarization is related to the alignment of the dipoles with the applied field. The polarization phenomena include interfacial polarization, dipolar polarization, ionic polarization, and electronic polarization. All these polarizations occur in same order as mentioned in different time domains.

Increasing trend of ac electrical conductivity $\left(\sigma_{\mathrm{ac}}\right)$ at higher frequencies was observed while linear trend was 


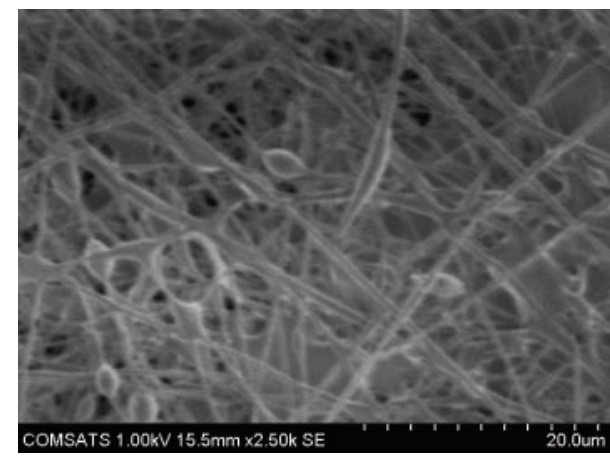

(a)

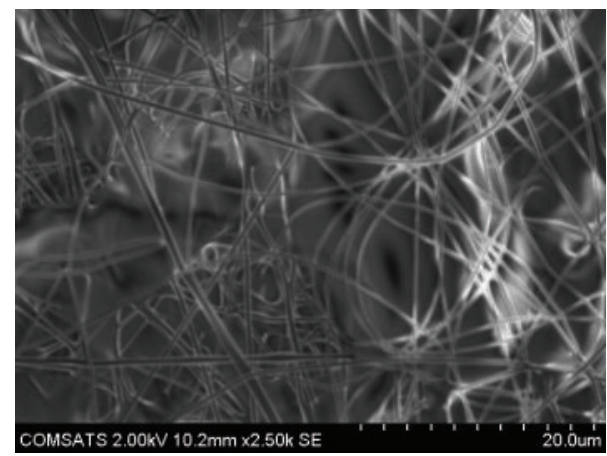

(b)

FIGURE 5: SEM micrographs of (a) polymer nanofibers and (b) composite nanofibers of $\mathrm{NaCoO}_{2}$.

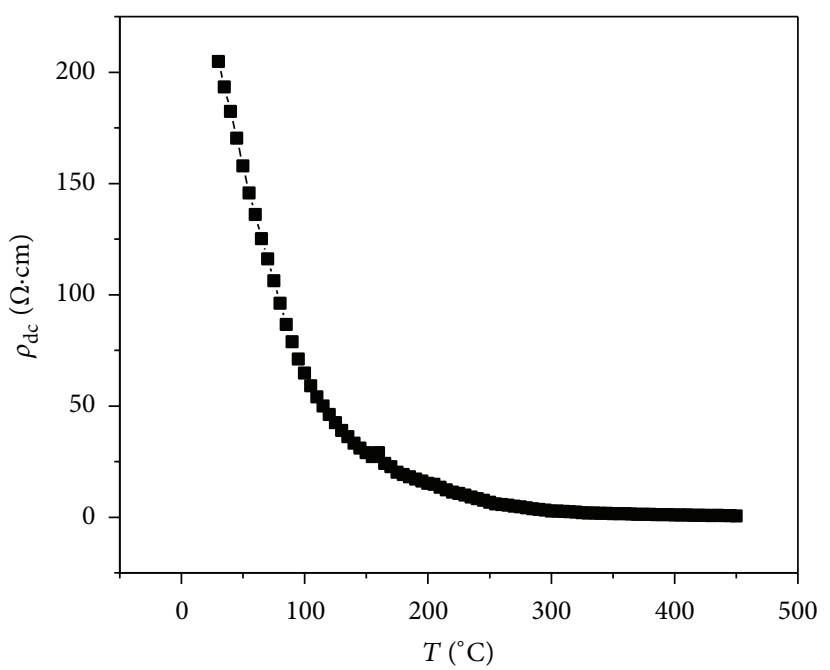

(a)

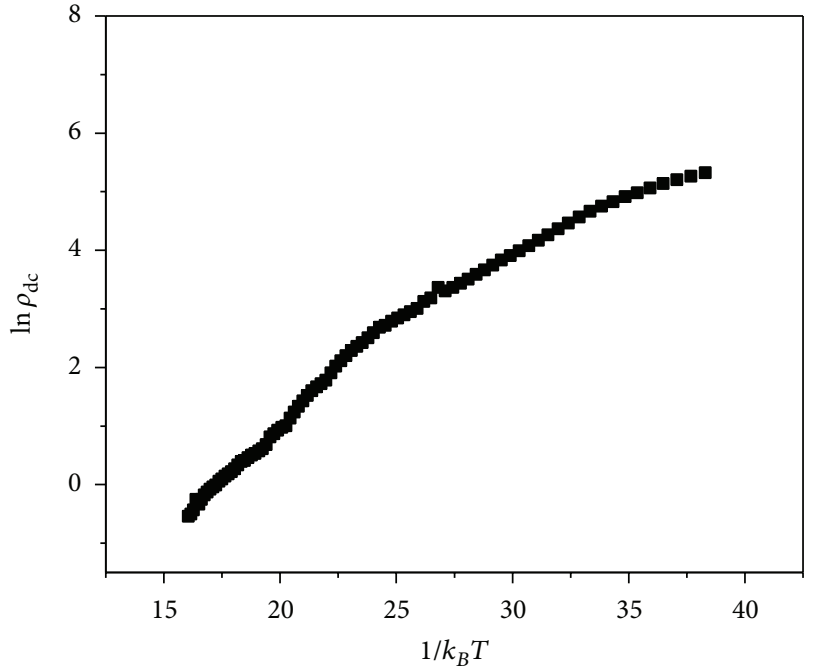

(b)

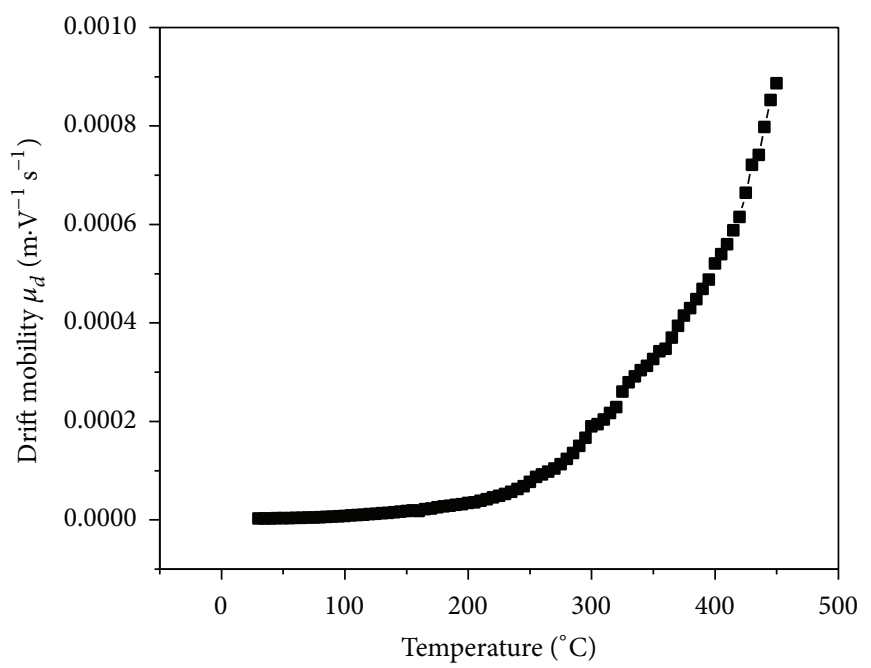

(c)

Figure 6: Variation in dc resistivity $\left(\rho_{\mathrm{dc}}\right)$ with temperature (a), Arrhenius plot for determination of activation energy $\left(E_{g}\right)(\mathrm{b})$, and drift mobility $\mu_{d}$ as a function of temperature for $\mathrm{NaCoO}_{2}$ (c). 


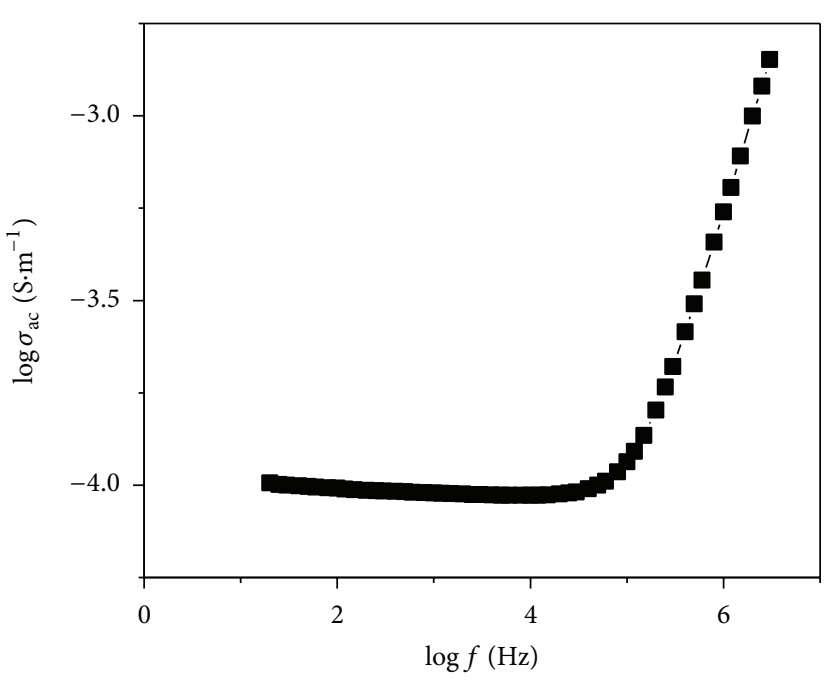

(a)

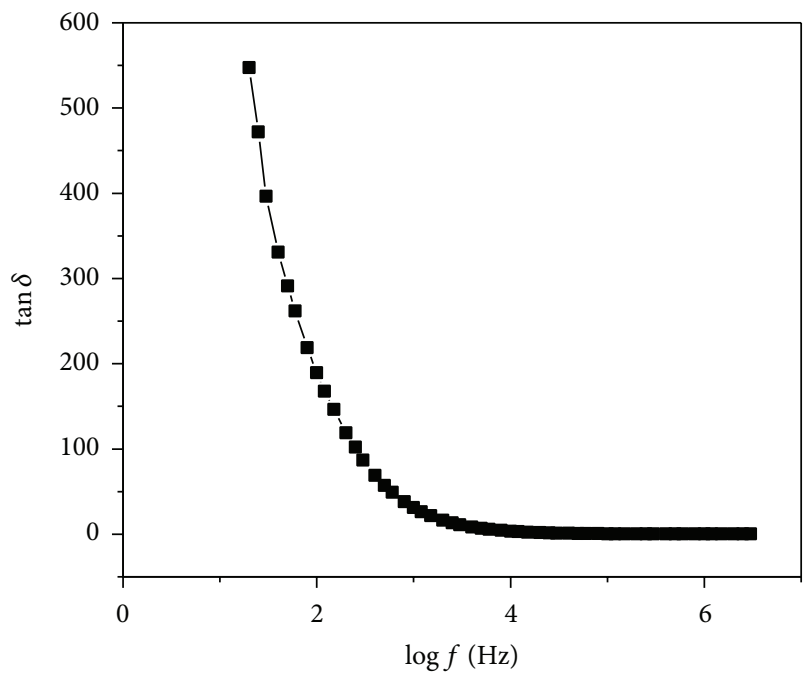

(b)

FIgURE 7: $\log f$ versus $\log$ ac conductivity $\left(\sigma_{\mathrm{ac}}\right)(\mathrm{a})$ and $\log f$ versus dielectric loss $\tan \delta$ (b) of nanoparticles of $\mathrm{NaCoO}_{2}$.

observed at lower frequencies (Figure 7(a)). AC electrical conductivity was calculated using the following given formula:

$$
\sigma_{\mathrm{ac}}=\omega \mathcal{\varepsilon}^{\prime} \tan \delta .
$$

The given relationship interprets that the ac electrical conductivity is directly dependent on the dielectric loss tangent $(\tan \delta)$ as well as the dielectric constant $(\hat{\varepsilon})$ of the material. The ac electrical conductivity increased at higher frequency due to increase in hopping mechanism. The hopping of ions directly influences the ac conductivity of the material. The hopping mechanism is not influential enough at lower frequencies therefore linear trend of the ac conductivity was observed at lower frequency range. Interfacial polarization occurs due to the accumulation of charge carriers either at the surface of the material or at the grain as well as interfacial boundaries with applied electric field.

Figure 7(b) shows the dielectric loss tangent plot of the prepared sample. The losses mainly correspond to the lagging and leading of the current and voltage. The angle by which current lags behind the voltage refers to the dielectric loss tangent $(\tan \delta)$ of the material. In an ideal case when there will be no losses, the angle between the voltages and current will be $90^{\circ}$ while it will alter with losses. Decreasing trend of the losses was observed with increase in frequency. Dielectric loss corresponds to the ratio between energy loss to energy stored per ac cycle of applied electric field. There are different reasons behind the dielectric losses of the material and the major among them is the polarization. Losses occur when the intrinsic dipoles of a material tend to align themselves according to the frequency of the applied field.

3.5. Electrical Properties of Composite Nanofibers. The prepared composites of the respective particles were analyzed for the ac electrical properties at room temperature within a frequency range of $20 \mathrm{~Hz}-3 \mathrm{MHz}$. Figures 8 (a) and 8(b) show the plots for ac electrical properties of the prepared composite nanofibers. AC electrical conductivity (Figure 8(a)) showed the same trend as that of particles following the similar polarization and relaxation mechanisms mentioned in the previous section. It increased at higher frequency region due to the enhancement in the hopping mechanism, while at lower frequencies it remained linear. Figure 8(b) shows the dielectric loss tangent $(\tan \delta)$ of the composite nanofibers. The dielectric losses showed the decreasing trend with increase in frequency. At lower frequency, a peak was observed which corresponded to the interfacial polarization, while at higher frequency another relaxation peak was observed that corresponded to the dipolar polarization. The peak may extend to higher frequencies which were out of our measurement range in this case.

Comparative to the respective particles, it was observed that the dielectric losses and as a consequence ac electrical conductivity were lower for the composite nanofibers.

3.6. Thermal Transport Properties. Thermal transport properties of the prepared particles and their composite nanofibers were studied at room temperature. Thermal transport properties including thermal conductivity $(\lambda)$, thermal diffusivity $(\kappa)$, and volumetric heat capacity $\left(\rho C_{p}\right)$ were measured using Advantageous Transient Plane Source (ATPS) technique. In ATPS method, three-dimensional heat flows inside the material. Electrically conducting pattern of bifilar spiral is used in this method. This conducting pattern is coated with the thin insulator layer of Kapton (electrically insulator but thermally conductor) [16, 17]. The TPS element is used as both heat source and temperature sensor in this method [18-21].

The thermal conductivity of the particles of $\mathrm{NaCoO}_{2}$ was observed to be $0.610 \mathrm{~W} / \mathrm{m}-\mathrm{K}$ while for composite nanofibers it was observed to be higher $(1.129 \mathrm{~W} / \mathrm{m}-\mathrm{K})$. The thermal conductivity of the composite nanofibers increased due the 


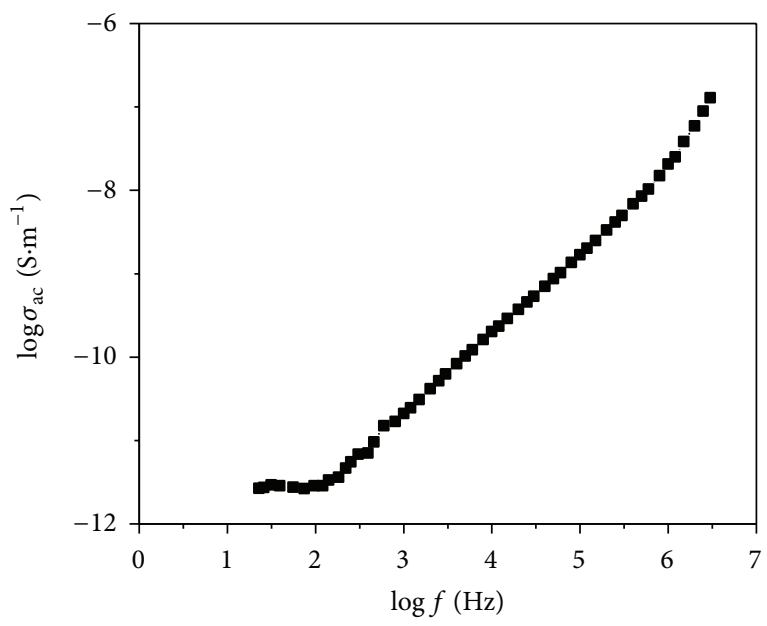

(a)

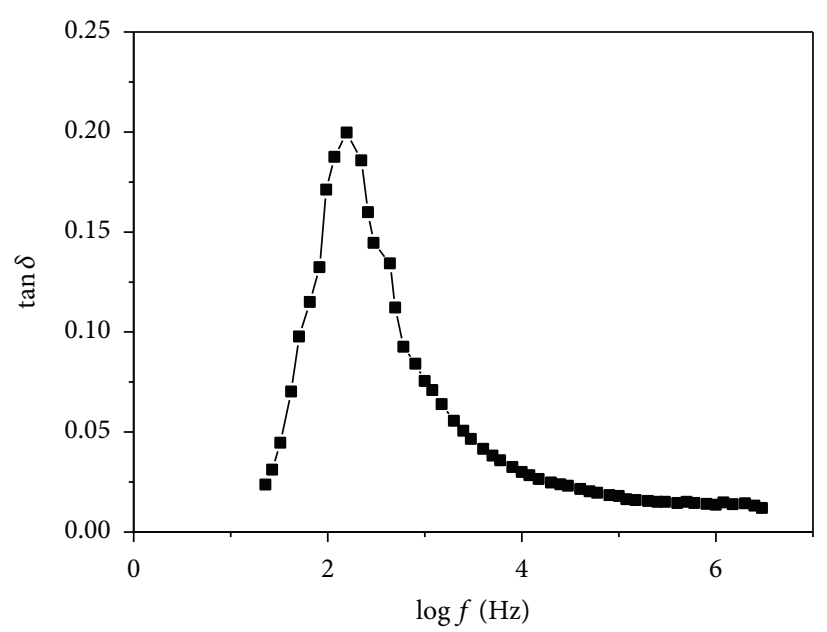

(b)

Figure 8: $\log f$ versus $\log$ ac conductivity $\left(\sigma_{\mathrm{ac}}\right)$ (a) and $\log f$ versus dielectric $\operatorname{loss} \tan \delta$ (b) of composite nanofibers of PVA:NaCoO . $_{2}$

combined effect of PVA polymer with the nanoparticles of $\mathrm{NaCoO}_{2}$. Thermal conductivity in a material is dependent on the electron as well as phonon scatterings. Reduced phonon scatterings due to improved connectivity of grains has increased the thermal conductivity in nanofibers.

Thermal diffusivity is the area of the sample influenced by the applied heat in unit time. It was higher for the particles $\left(1.371 \mathrm{~mm}^{2} / \mathrm{s}\right)$ while for composite nanofibers it was lower $\left(0.729 \mathrm{~mm}^{2} / \mathrm{s}\right)$. Volumetric heat capacity $\left(\rho C_{p}\right)$ was calculated using the thermal conductivity $(\lambda)$ and thermal diffusivity $(\kappa)$ of the sample using the relationship

$$
\rho C_{p}=\frac{\lambda}{\kappa}
$$

Volumetric heat capacity $\left(\rho C_{p}\right)$ was lower for particles $\left(0.463 \mathrm{M}-\mathrm{J} / \mathrm{m}^{2}-\mathrm{K}\right)$ while higher for composite nanofibers $\left(1.548 \mathrm{M}-\mathrm{J} / \mathrm{m}^{2}-\mathrm{K}\right)$. Volumetric heat capacity refers to the capacity of the energy storage of the sample. Increased volumetric heat capacity is indicating the higher storage capability as compared to the counterpart nanoparticles.

\section{Conclusions}

The nanoparticles of $\mathrm{NaCoO}_{2}$ and their composite with polymer nanofibers were successfully prepared by sol-gel method and sol-gel combined electrospinning technique, respectively. XRD, SEM, and TGA-DSC were done to analyze the structural and morphological properties of the prepared sample. XRD analysis confirmed that nanoparticles possessed orthorhombic crystal structure while their composite possessed hexagonal crystal structure. No impurity peak was observed in both cases. The crystallite size was in the range of $32-46 \mathrm{~nm}$ for particles while for composite nanofibers it was in the range of $42-82( \pm 1) \mathrm{nm}$. SEM micrographs of particles showed the fine morphology and homogeneous particle size distribution. SEM micrographs of composite nanofibers confirmed the fine morphology possessing the average diameter of $128 \mathrm{~nm}$. TGA-DSC was done for the particles sample. The crystallinity was observed above $300^{\circ} \mathrm{C}$ and at $700^{\circ} \mathrm{C}$ melting peak was observed. AC and dc electrical analysis was done for particles and their composites as a function of frequency and temperature, respectively. Dielectric losses were found to be decreasing with increasing frequency. Comparatively, $\tan \delta$ were higher for particles as compared to their composite nanofibers. Thermal conductivity of the prepared samples was measured using ATPS technique. It was observed that particles sample possessed low thermal conductivity $(0.610 \mathrm{~W} / \mathrm{m}-\mathrm{K})$ as compared to that of composite nanofibers $(1.129 \mathrm{~W} / \mathrm{m}-\mathrm{K})$.

\section{Conflict of Interests}

The authors declare that there is no conflict of interests regarding the publication of this paper.

\section{Acknowledgments}

Dr. A. Asif and Dr. A. Anwar of IRCBM, CIIT, Lahore, Pakistan, are acknowledged for DSC/TGA data.

\section{References}

[1] G. J. Snyder and E. S. Toberer, "Complex thermoelectric materials," Nature Materials, vol. 7, no. 2, pp. 105-114, 2008.

[2] D. Zhao and G. Tan, "A review of thermoelectric cooling: materials, modeling and applications," Applied Thermal Engineering, vol. 66, no. 1-2, pp. 15-24, 2014.

[3] E. S. Jeong, "A new approach to optimize thermoelectric cooling modules," Cryogenics, vol. 59, pp. 38-43, 2014.

[4] Y. Du, S. Z. Shen, K. Cai, and P. S. Casey, "Research progress on polymer-inorganic thermoelectric nanocomposite materials," Progress in Polymer Science, vol. 37, no. 6, pp. 820-841, 2012.

[5] H. Yakabe, K. Kikuchi, I. Terasaki, Y. Sasago, and K. Uchinokura, "Thermoelectric properties of transition metal oxides $\mathrm{NaCO}_{2} \mathrm{O}_{4}$ system," in Proceedings of the 16th International 
Conference on Thermoelectrics, pp. 523-527, Dresden, Germany, August 1997.

[6] P. Zhu, T. Takeuchi, H. Ohta, W.-S. Seo, and K. Koumoto, "Preparation and thermoelectric properties of $\mathrm{Na}_{x} \mathrm{CoO}_{2} /$ $\mathrm{Co}_{3} \mathrm{O}_{4}$ layered nano-composite," Materials Transactions, vol. 46, no. 7, pp. 1453-1455, 2005.

[7] S. Ramakrishna, K. Fujihara, W. E. Teo, T. C. Lim, and Z. Ma, An Introduction to Electrospinning and Nanofibers, World Scientific, Singapore, 2005.

[8] W. E. Teo and S. Ramakrishna, "A review on electrospinning design and nanofibre assemblies," Nanotechnology, vol. 17, no. 14, pp. R89-R106, 2006.

[9] A. S. Saleemi, A. Abdullah, S. M. H. Shah, and M. Anis-UrRehman, "Electrospun proficient polymer based nano fibers with ceramic particles," Journal of Superconductivity and Novel Magnetism, vol. 26, no. 4, pp. 1027-1030, 2013.

[10] D. Li, J. T. McCann, and Y. Xia, "Electrospinning: a simple and versatile technique for producing ceramic nanofibers and nanotubes," in Progress in Nanotechnology: Processing, John Wiley \& Sons, London, UK, 2010.

[11] M. OkanErdal, M. Koyuncu, and I. Uslu, "High thermoelectric performance of unsintered $\mathrm{NaCo}_{2} \mathrm{O}_{4}$ nanocrystal," International Journal of Scientific \& Technology Research, vol. 4, no. 4, pp. 37-39, 2015.

[12] R. J. Kline, M. D. McGehee, E. N. Kadnikova, J. Liu, and J. M. J. Fréchet, "Controlling the field-effect mobility of regioregular polythiophene by changing the molecular weight," Advanced Materials, vol. 15, no. 18, pp. 1519-1522, 2003.

[13] J. Zhao, J. Jiang, N. Wei, Y. Zhang, and T. Rabczuk, “Thermal conductivity dependence on chain length in amorphous polymers," Journal of Applied Physics, vol. 113, no. 18, p. 184304, 2013.

[14] H. Zhao, M. Pokharel, G. Zhu et al., "Dramatic thermal conductivity reduction by nanostructures for large increase in thermoelectric figure-of-merit of $\mathrm{FeSb}_{2}$," Applied Physics Letters, vol. 99, Article ID 163101, 2011.

[15] Y. Hiroshige, M. Ookawa, and N. Toshima, "High thermoelectric performance of poly(2,5-dimethoxyphenylenevinylene) and its derivatives," Synthetic Metals, vol. 156, no. 21-24, pp. 1341-1347, 2006.

[16] M. A. Kamarudin, S. R. Sahamir, R. S. Datta, B. D. Long, M. F. M. Sabri, and S. M. Said, "A review on the fabrication of polymerbased thermoelectric materials and fabrication methods," The Scientific World Journal, vol. 2013, Article ID 713640, 17 pages, 2013.

[17] A. Maqsood, M. Anis-ur-Rehman, V. Gumen, and Anwar-ulHaq, "Thermal conductivity of ceramic fibres as a function of temperature and press load," Journal of Physics D: Applied Physics, vol. 33, no. 16, pp. 2057-2063, 2000.

[18] M. Anls-ur-Rehman, A. Rasool, and A. Maqsood, "Thermal transport properties of synthetic porous solids as a function of applied pressure," Journal of Physics D: Applied Physics, vol. 32, no. 18, article 2442, 1999.

[19] M. Anis-ur-Rehman and A. Maqsood, "A modified transient method for an easy and fast determination of thermal conductivities of conductors and insulators," Journal of Physics D: Applied Physics, vol. 35, no. 16, pp. 2040-2047, 2002.

[20] G. P. Joshi, N. S. Sexena, and R. Mangal, “Temperature dependence of effective thermal conductivity and effective thermal diffusivity of Ni-Zn ferrites," Acta Materialia, vol. 51, no. 9, pp. 2569-2576, 2003.
[21] M. Anis-ur-Rehman and A. Maqsood, "Measurement of thermal transport properties with an improved transient plane source technique," International Journal of Thermophysics, vol. 24, no. 3, pp. 867-883, 2003. 

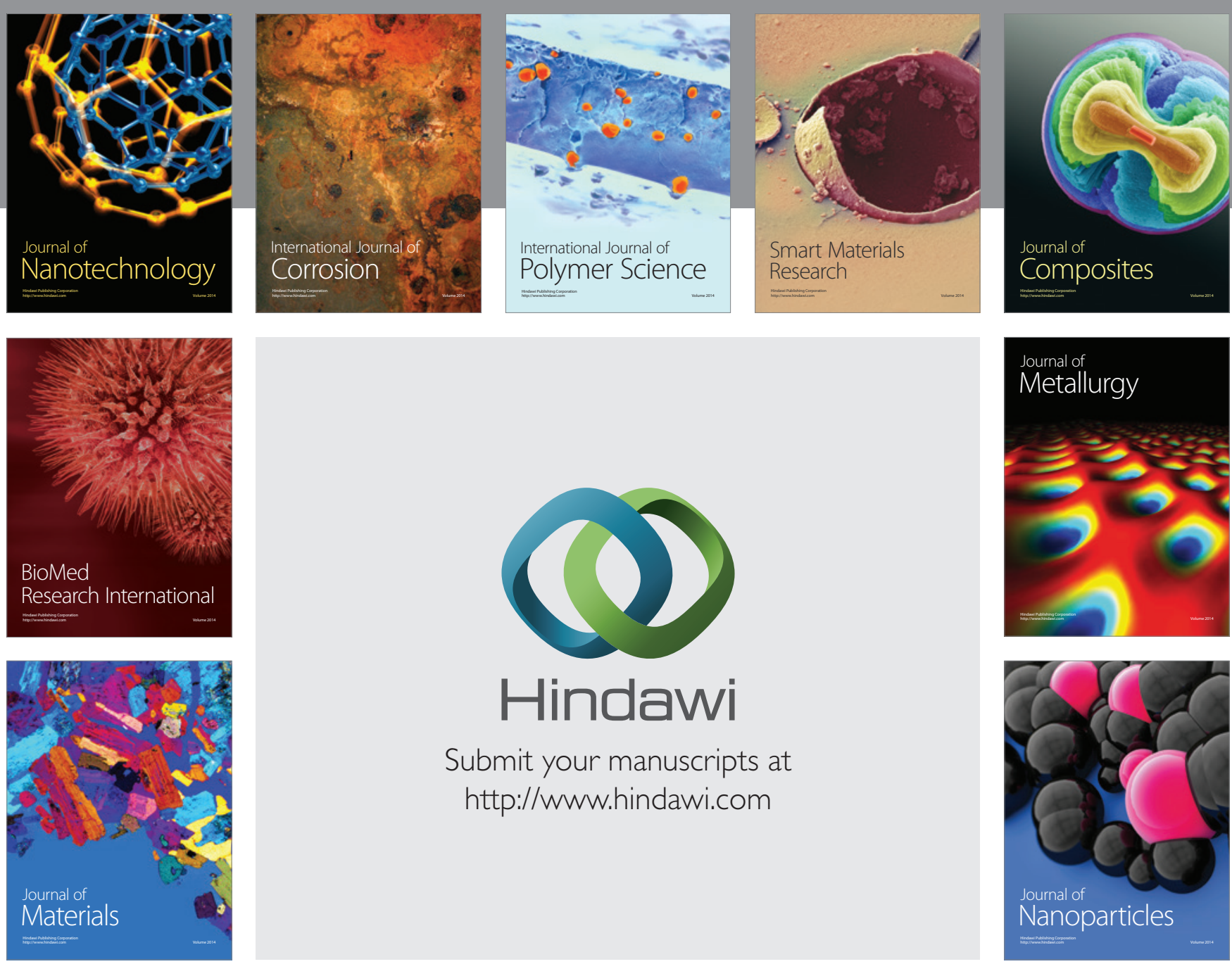

Submit your manuscripts at http://www.hindawi.com
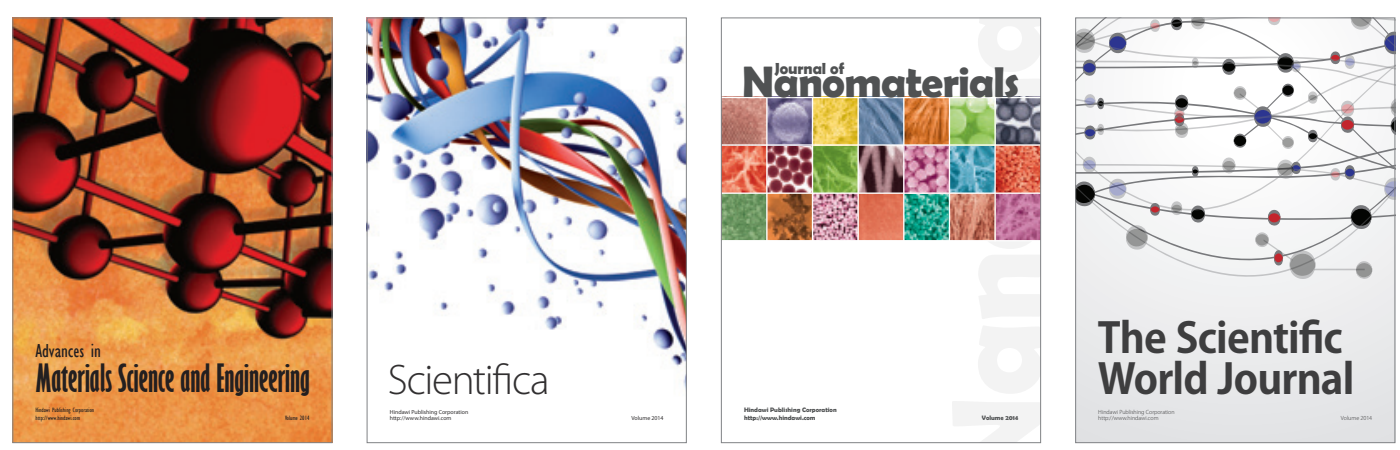

\section{The Scientific World Journal}
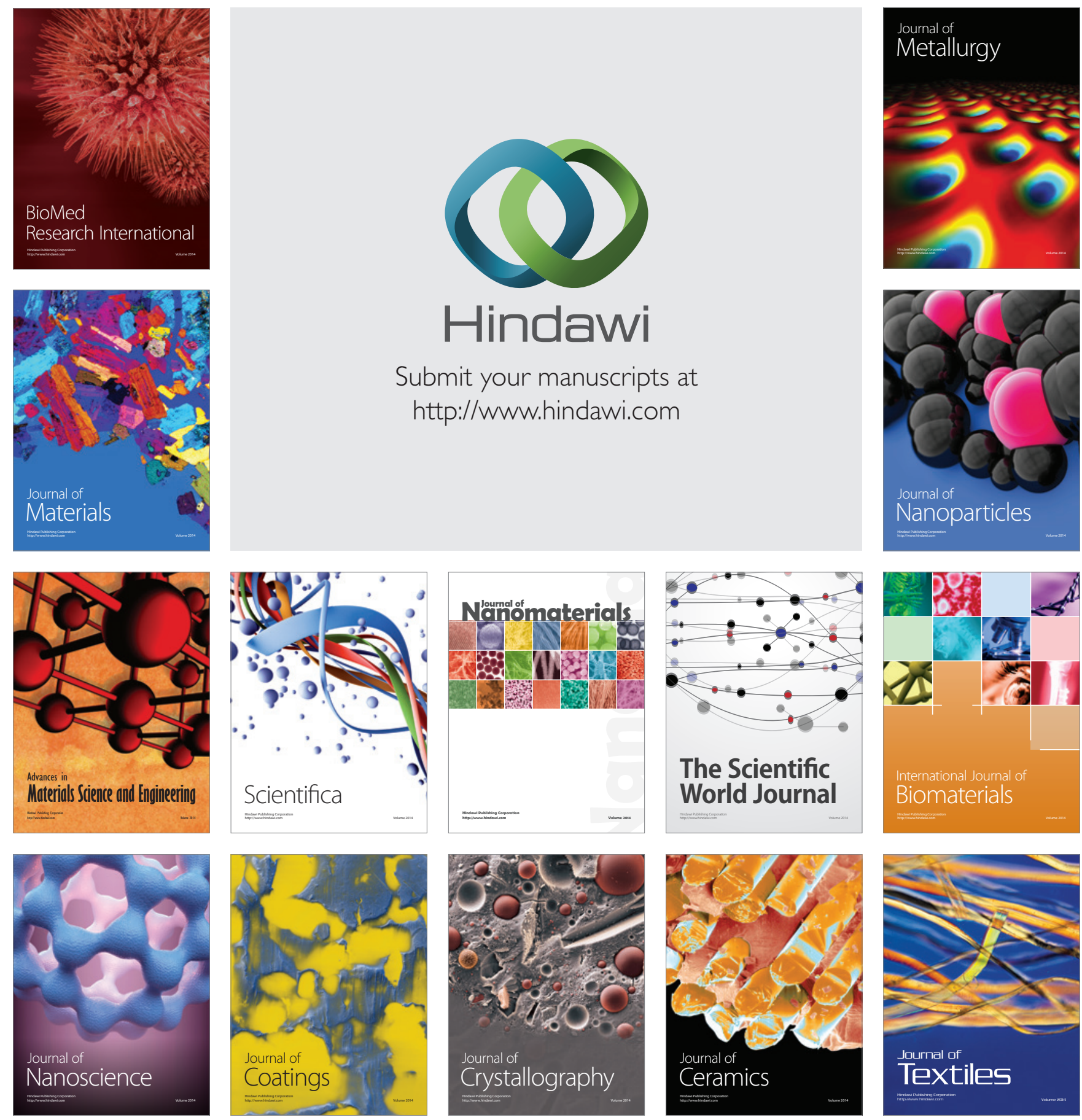